\title{
Severity Analysis of Debris Flow Hazards in Chengkang Railway Based on G1-ANP and Improved Radar Chart
}

\author{
Yanjin WANG, Rongchang $\mathrm{GUO}^{1}$ and Xiaochun WU \\ School of Automatic \& Electrical Engineering, Lanzhou Jiaotong University, Lanzhou \\ 730070, China
}

\begin{abstract}
Debris flow causes huge casualties and economic losses to railway construction and transportation every year, so it is of great significance to analyze the severity of debris flow to reduce the loss. For the debris flow hazards severity analysis, an integrated approach based on G1-ANP was proposed. Firstly, under the condition of the environmental risk, induced conditional risk, and vulnerability risk, the 16 index factors have been selected, for example, the degree of slope, land use type, flow accumulation, and annual mean rainfall. Then, considering the interaction among risk factors, a multi-level G1-ANP risk factor structure model has been established based on the criteria of buried capacity, impact velocity, and scouring distance (or area) of debris flow and the solution process of the model was described. Finally, the risk severity and the proportion of the various risks for each section were calculated using the weighted method. The analysis results are shown in the improved radar chart. The results show that the overall severity of debris flow in the Chengkang railway is not very high. The results can provide a reference for the management of debris flow hazards prevention and reduce the losses caused by hazards in railway operation.
\end{abstract}

Keywords. Chengkang Railway, debris flow, G1-ANP, radar map, risk factors

\section{Introduction}

As the second "sky road" to enter Tibet after the Qinghai-Tibet Railway, Sichuan-Tibet Railway can not only promote national unity but also drive the economic development of Tibet. The geological structure along the Sichuan-Tibet Railway is active with high terrain and large slopes characteristics[1], and there are geologic hazards such as earthquakes, landslides, debris flows. Among them, debris flows are serious natural hazards and occur more frequently. It seriously damages the traffic environment and threatens people's lives and property safety. The severity analysis results of debris flow hazards can provide a reference for the risk control of debris flow hazards along the route and play an important role in the construction and operation to take hazards prevention and control measures to avoid, transfer and reduce the risk.

There are numerous literatures on the severity of debris flow, the historical hazard and potential hazard analysis methods of debris flow hazards have been provided by Fei Duqiu which constructed an index system for physical exposure, hazards bearing

${ }^{1}$ Guo Rongchang, School of Automatic \& Electrical Engineering, Lanzhou Jiaotong University, Lanzhou 730070, ChinaE-mail:2485307443@qq.com 
capacity and vulnerability and debris flow along the railway was obtained[2]. Li Xinyang built a risk assessment indicator system for the debris flow of Ya'an City, Sichuan Province, by using AHP (Analytic Hierarchy Process) to assign weights to each evaluation factor[3]. Li Yimin established an evaluation system for the susceptibility of debris flow hazards of Lushui city by using a certain factor model. The research object was divided into four levels[4]. Lin Hongyu used the Tan Bingyan scoring method to quantitatively evaluate the severity of typical debris flow gullies. The results show that the debris flows in the upper reaches of Minjiang River are mainly medium risk[5]. However, these authors could not consider the correlation and influence among the factors when researching debris flow hazards index factors, and few studies directly show the result of debris flow hazards severity. The risk factors of debris flow hazards were analyzed based on G1-ANP (Order Relation Analysis Method, Network Analysis Method), and the weights of each factor were obtained. The weighted method was used to obtain the debris flow hazards severity grade of each section and the improved radar map evaluation method was used to present the evaluation results directly. Compared with the debris flow risk zoning map of Sichuan Province, the rationality and accuracy of the calculation results are explained.

\section{Analysis Method}

\subsection{Severity Related Factors}

There are three factors of debris flow occurrence, namely topography and landforms, material sources and induced causes. The influence of each factor on the research object is considered when analyzing the severity of debris flow hazards risk. Degree of slope can provide a certain amount of energy for the occurrence of debris flow, land use type, formation lithology, and soil type affect the material source of the debris flow. The occurrence of debris flows is influenced by flow accumulation and average mean rainfall. The altitude of the railway and the type of the railway are also closely related to the damage of the railway after the occurrence of debris flow. Under the same conditions, the damage of the tunnel is less than that of bridge and subgrade, but the tunnel entrance is often blocked seriously.

\subsection{G1 Method}

G1 method, also known as order relation analysis method, which is a subjective weight determining method[6]. In this method, the index weight is determined by first sequencing the index importance and then followed by estimating the relative degree of importance between the adjacent sequenced indexes[7]. The basic calculation steps are as follows:

(1) Determine the order relationship among indicators

Assuming that there are $n(n \geq 2)$ evaluation indexes, $x_{i}>x_{j}$ means that the importance of the $i$-th index is greater than that of the $j$-th index. If a relationship $\boldsymbol{x}_{1}^{\prime}>\boldsymbol{x}_{2}^{\prime}>\cdots>\boldsymbol{x}_{n}^{\prime}$ is established, the order relation of evaluation index is established, $\boldsymbol{x}_{\boldsymbol{1}}^{\prime}(\boldsymbol{n} \geq \boldsymbol{i} \geq \mathbf{1})$ represents the $i$-th evaluation index in order relation.

(2) Determine the relative importance of indicators 
The rational judgment value of the importance degree of adjacent evaluation indexes $\boldsymbol{x}_{\boldsymbol{k}-1}^{\prime}$ and $\boldsymbol{x}_{\boldsymbol{k}}^{\prime}$ in the order relation of experts is set as:

$$
w_{k-1} / w_{k}=r_{k}(k=n, n-1, \cdots, 2)
$$

In which $\boldsymbol{w}_{\boldsymbol{k}}$ represents the weight of the $k$-th index in the order relation, the assignment of $\boldsymbol{r}_{\boldsymbol{k}}$ is changed from 1 to 9 in AHP to 1.0 to 1.8 , that is, the same nine scales.

(3) Calculate weight coefficient

The weight calculation formula of the $n$-th evaluation index is,

$$
w_{n}=\left(1+\sum_{k=2}^{n} \prod_{i=k}^{n} r_{i}\right)^{-1}
$$

According to the formula for calculating $\boldsymbol{r}_{\boldsymbol{k}}$ in Eq. (2), the weights of indexes $n-1, n-2, \ldots, 2$ are calculated in turn. Because $\sum_{k=1}^{n} w_{k}=1$, the weight of the first index can be obtained as well.

\subsection{ANP}

In the 1990s, Professor TLSatty of the United States elaborated on the theory and method of ANP in detail [8,9]. ANP divides the system elements into the control layer and network layer, where the control layer includes objectives and decision criteria. The network layer is composed of all the elements controlled by the control layer. Each criterion dominates an interdependent and feedback network structure[10].

\subsection{G1-ANP Model}

G1 method is combined with ANP because G1 method can ensure the consistency of judgment matrix when determining the weight and ANP can consider the mutual influence and correlation of each index under multi-criteria, so G1-ANP model not only reflects the characteristics of network analysis method but also omits the tedious steps of consistency test and adjustment of an unqualified judgment matrix.

\subsection{Improved Radar Chart Method}

In different improvement methods, the comprehensive evaluation function is also not the same [11,12]. Considering the differences of topography, annual rainfall and other factors of different sections of the line, as well as the visualization of evaluation results, a comprehensive evaluation radar map is formed as shown in Figure 1. The calculation formulas are: 


$$
\begin{aligned}
\boldsymbol{S}_{i} & =\frac{1}{2} \pi \boldsymbol{R}_{i}^{2} \\
\boldsymbol{S}_{i j} & =\frac{1}{2} \pi \boldsymbol{R}_{i j}^{2} \omega_{i j}=\frac{1}{2} \pi \boldsymbol{R}_{i j}^{2} \frac{\alpha_{i j}}{2 \pi} \\
\boldsymbol{R}_{i} & =\sum_{m=1}^{16} \boldsymbol{Q}_{m} \boldsymbol{Z}_{m} \\
\boldsymbol{R}_{i j} & =\sum_{m=1}^{k} \frac{\boldsymbol{Q}_{m}}{\sum_{m=1}^{k} \boldsymbol{Q}_{m}} \boldsymbol{Z}_{m}
\end{aligned}
$$

$i$ represents the number of research objects, $j$ represents the number of risk categories included in the research object, $S_{i}$ means the overall severity of the $i$-th research subject, $S_{i j}$ means the various risk severity of the research subjects. $R_{i}$ represents the radius corresponding to the overall severity of the $i-t h$ object, and $R_{i j}$ represents the radius corresponding to various risks of the object, $m$ is the number of evaluation indicators, $k$ is the number of factors under the kinds of $j$ risk. $Q_{m}$ is the weight of the $\mathrm{m}$ factor, $Z_{m}$ is the data amount of the $m$ factor.

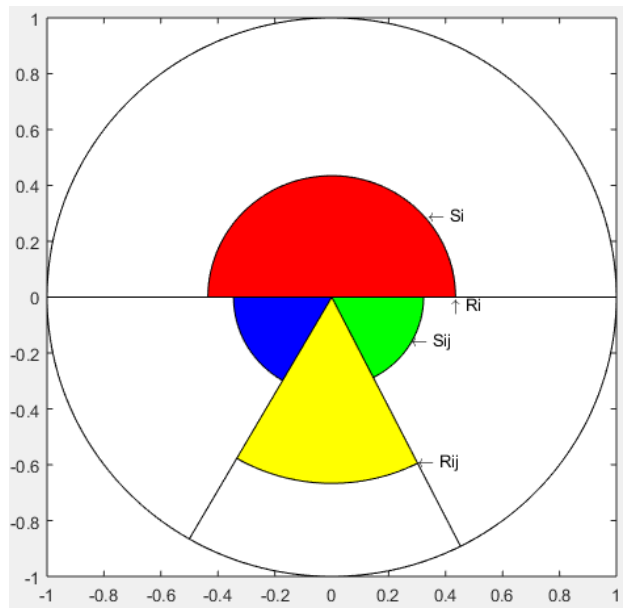

Figure 1. Comprehensive evaluation radar chart

\subsection{Comprehensive Analysis Process}

The data of each evaluation factor is integrated and quantified and divided into five grades corresponding to the severity grade. The risk severity of debris flow hazards in each section is calculated by the weighted calculation of each factor, and the debris flow hazards severity grade of each section is obtained according to the risk severity grade table. 


\section{Comprehensive Analysis Model}

\subsection{Establish Index System for Hazards Risk Assessment}

In the construction of hazards risk evaluation index system, combined with previous research results, the index system is divided into target layer $\mathrm{x}$, criterion layer $\mathrm{y}$ and factor layer z. As shown in Table 1.

Table 1 Index system of risk assessment of debris flow hazards

\begin{tabular}{lll}
\hline Target layer $\mathbf{X}$ & Criterion layer $\mathbf{Y}$ & Factor layer $\mathbf{Z}$ \\
\hline & & Distance to fault $Z_{1}$ \\
& & Formation lithology $Z_{2}$ \\
& & Relative height difference $Z_{3}$ \\
& Environmental risk $Y_{1}$ & Elevation $Z_{4}$ \\
& Degree of slope $Z_{5}$ \\
& Slope direction $Z_{6}$ \\
& Land use type $Z_{7}$ \\
Debris flow hazards risk & River valley density $Z_{8}$ \\
assessment $X$ & Soil type $Z_{9}$ \\
& & Flow accumulation $Z_{10}$ \\
& Seismicity $Z_{11}$ \\
& Induced conditional risk $Y_{2}$ & Annual mean rainfall $Z_{12}$ \\
& & Distance to river $Z_{13}$ \\
& & Distance to line $Z_{14}$ \\
& & Line altitude $Z_{15}$ \\
& Vulnerability risk $Y_{3}$ & Height difference from ground $Z_{16}$ \\
\hline
\end{tabular}

\subsection{Construct G1-ANP Model}

The G1-ANP model is constructed by considering the interaction of various factors, as shown in Figure 2.

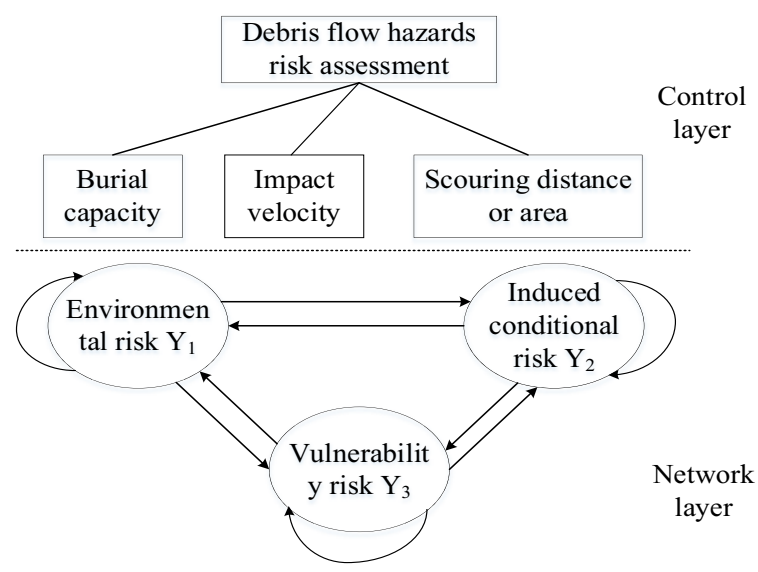

Figure 2. G1-ANP model of debris flow hazards risk

\subsection{Generate risk Level Table}

According to Railway application-The specification and demonstration of Reliability, Availability, Maintainability and Safety(RAMS), Grading methods of natural hazards 
risk, Railway Traffic Accident Handling Rules and other relevant specifications, a severity rating table is established, which takes the number of deaths or serious injuries, the interruption time of line traffic and the number of people who need to be transferred or rescued as indicators. As shown in Table 2.

Table 2. Debris flow hazards severity grade table

\begin{tabular}{|c|c|c|c|}
\hline \multirow[b]{2}{*}{ Severity level } & \multicolumn{3}{|c|}{ Consequence indicators } \\
\hline & $\begin{array}{l}\text { Number of deaths or } \\
\text { serious injuries }\end{array}$ & $\begin{array}{l}\text { Interruption time of } \\
\text { the line }\end{array}$ & $\begin{array}{l}\text { Number of people in need } \\
\text { of transfer or assistance }\end{array}$ \\
\hline $\begin{array}{l}\text { Particularly serious } \\
\text { accident }\end{array}$ & $\begin{array}{l}\text { Death:>30; } \\
\text { Serious injuries:>50. } \\
\text { Death:5 30; }\end{array}$ & More than a week & More than 100,000 \\
\hline Major accident & $\begin{array}{l}\text { Serious inju- } \\
\text { ries:30 50. } \\
\text { Death: }<5\end{array}$ & More than 48 hours & 50,000 to 100,000 \\
\hline Serious accident & $\begin{array}{l}\text { Serious inju- } \\
\text { ries:10 30. }\end{array}$ & More than 24 hours & 20,000 to 50,000 \\
\hline Dangerous accident & $\begin{array}{l}\text { Death:0; } \\
\text { Serious injuries: }<10 \text {. }\end{array}$ & More than 6 hours & 1,000 to 20,000 \\
\hline General accident & $\begin{array}{l}\text { Death: } 0 \text {; } \\
\text { Serious injuries: } 0 \text {. }\end{array}$ & More than 2 hours & Less than 1,000 \\
\hline
\end{tabular}

\section{Case Analysis}

\subsection{Calculation and Analysis}

\subsubsection{Building Hypermatrix}

The ANP matrix is constructed by referring to the situation of similar areas and relevant historical data. The normalized weight vector is calculated by eigenvalue method to form the judgment matrix:

$$
\boldsymbol{w}_{12}=\left[\begin{array}{llll}
0.0352 & 0.1553 & 0.0290 & 0.0350 \\
0.0481 & 0.2220 & 0.0509 & 0.0507 \\
0.2229 & 0.0738 & 0.0741 & 0.0739 \\
0.0249 & 0.0183 & 0.0181 & 0.0247 \\
0.3132 & 0.1074 & 0.2210 & 0.2223 \\
0.0184 & 0.3114 & 0.3091 & 0.3121 \\
0.1557 & 0.0246 & 0.1076 & 0.1075 \\
0.0740 & 0.0349 & 0.0351 & 0.0183 \\
0.1077 & 0.0524 & 0.1550 & 0.1555
\end{array}\right]
$$

According to this method, $w_{11}, w_{13}, w_{21}, w_{22}, w_{23}, w_{31}, w_{32}, w_{33}$ are calculated by selecting the main criterion and the sub-criteria in turn, thus the factor layer hypermatrix is obtained. 


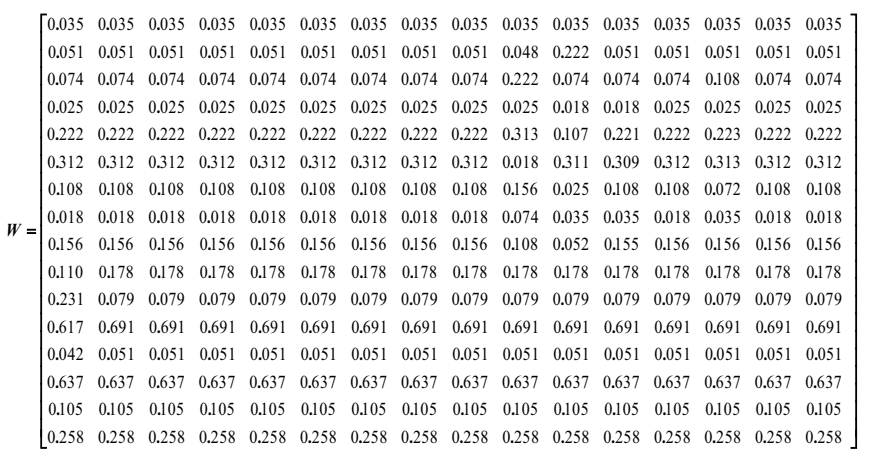

\subsubsection{Construction of the Criterion Layer Hypermatrix}

The judgment matrix of environmental risk $\mathrm{Y}_{1}$, induced conditional risk $\mathrm{Y}_{2}$ and vulnerability risk $\mathrm{Y}_{3}$ is established and the eigenvector corresponding to its maximum eigenvalue is calculated to form the weight matrix $y$ :

$$
y=\left[\begin{array}{lll}
y_{11} & y_{12} & y_{13} \\
y_{21} & y_{22} & y_{23} \\
y_{31} & y_{32} & y_{33}
\end{array}\right]=\left[\begin{array}{lll}
0.2385 & 0.6910 & 0.3196 \\
0.1365 & 0.2176 & 0.5584 \\
0.6250 & 0.0914 & 0.1220
\end{array}\right]
$$

The hypermatrix is obtained as:

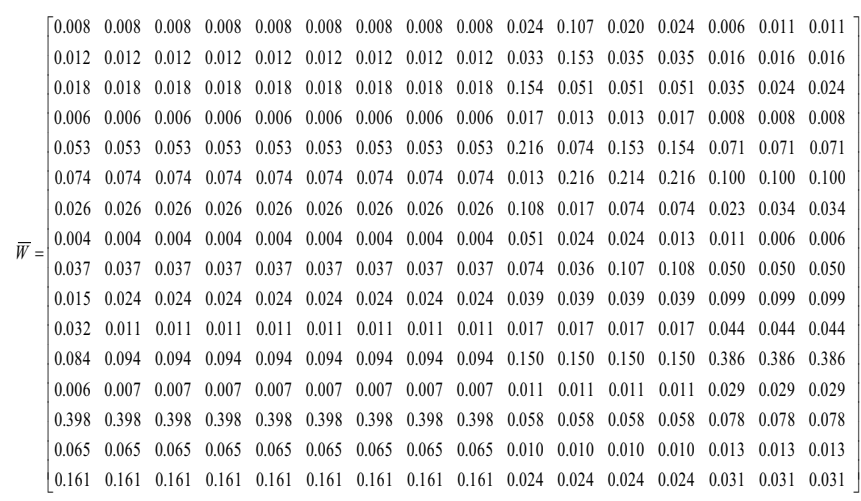

According to the data range, historical hazards data and expert opinion, the index data are divided into five levels corresponding to the severity level. The line is divided into sections for evaluation, and the data are weighted summation to obtain the severity level of the section.

\subsection{Application Example}

According to the comprehensive rating process, the weight of each factor is obtained as follows:

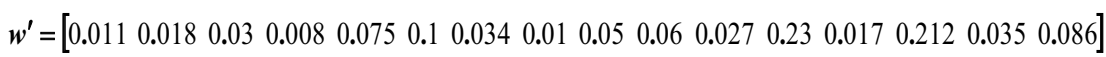


After weighted with the data, the severity levels of debris flow hazards in each section is obtained, as shown in Table 3, the result of radar chart is shown in Figure 3.

Table 3. Severity levels of debris flow hazards in each section of Chengkang section

\begin{tabular}{ll}
\hline Section & Severity level \\
\hline Chengdu to Shuangliu & 1.5 \\
Shuangliu to Xinjin & 1.2 \\
Xinjin to Pujiang & 1.1 \\
Pujiang to Mingshan & 1.7 \\
Mingshan to Yaan & 2.5 \\
Yaan to Tianquan & 3.5 \\
Tianquan to Luding & 3.2 \\
Luding to Kangding & 3.3 \\
\hline
\end{tabular}
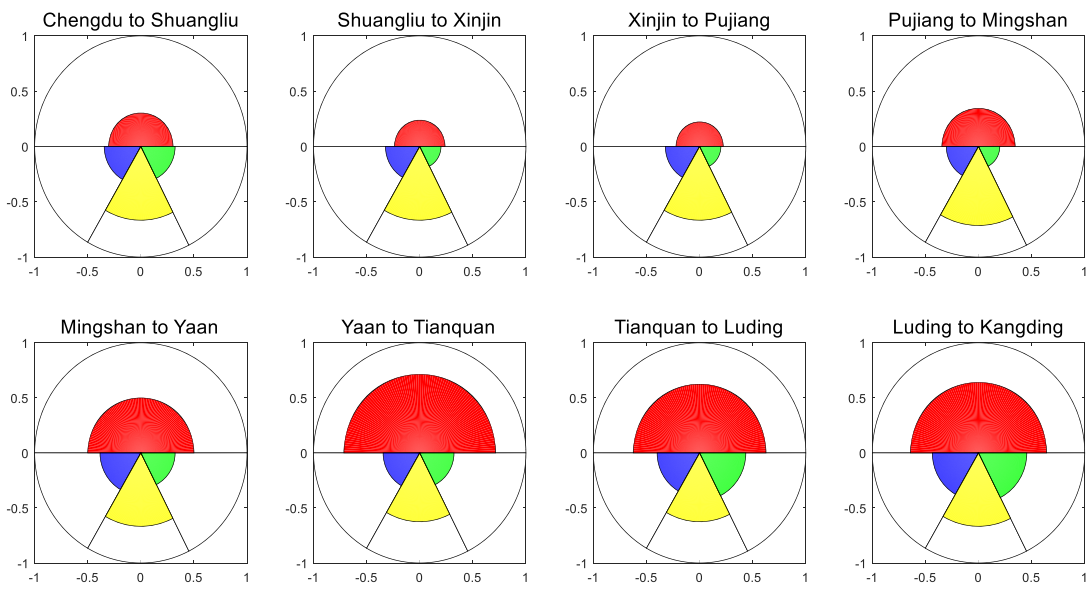

Figure 3. Radar chart of the severity of debris flow hazards in Chengkang section

\section{Conclusion}

Taking each section as the research object, the G1-ANP model is used to obtain the debris flow hazards severity of each section. Based on the analysis of hazard risk severity of debris flow along Chengkang section, the following conclusions are drawn:

(1) Among three risks of environmental risk, induced conditional risk and vulnerability risk of debris flow hazards, the annual mean rainfall of induced conditional risk account for a relatively large proportion, especially in the summer flood season, serious debris flow hazards are more likely to occur, that is, short-time heavy rainfall can easily cause debris flow hazards, so in the rainy season, debris flow hazards prevention should be strengthened.

(2) In the whole line of the Chengkang section, there are few sections with highrisk severity, which is because of the small change in altitude of this section compared with the Sichuan Tibet railway. The result also reflects the idea of "choose the place with fewer hazards to build railway" for Sichuan Tibet Railway. Ya'an, Tianquan and Luding have higher risk severity of debris flow hazards than other places. The result is basically matched to the debris flow risk zoning map of Sichuan Province, indicating the rationality of the analysis method. 
(3) The results of risk assessment can be visually displayed by the radar chart, that is, the severity level of debris flow hazards in each section can be directly seen from the radar chart. It can provide a reference for the protection and control of debris flow hazards in the railway operation. The analysis method is also applicable to other lines and other research fields.

\section{Acknowledgement}

Youth Science Fund Project of Lanzhou Jiaotong University(2018021)

\section{References}

[1] $\mathrm{Xu}$ YD, Yao LK. Some cognitions and thinkings about the specific Geo-environmental problems along the Sichuan-Tibet railway. Journal of Railway Engineering Society,2017,34(01):1-5+59.

[2] Fei DQ, Liu FG, Zhou Q, et al. Risk analysis of landslide and debris flow hazards along the QinghaiTibet Railway. Arid Land Geography,2016,39(02):345-352.

[3] Li XY, Liu QS, Bai SY, et al. Evaluation of debris flow hazard in Ya'an City of Sichuan Province. Bulletin of Soil and Water Conservation, 2017,37(02):278-283+288.

[4] Li YM, Li YH, Zhao ZH. Assessment on susceptibility of debris flow in Lushui based on the certain factor model. Research of Soil and Water Conservation,2019,26(04):336-342.

[5] Lin HY, Ding MT, Yu T, et al. Characteristic analysis and susceptibility assessment of the typical debris flow in the upper reaches of Min River. The Chinese Journal of Geological Hazard and Control,2017,28(04):6-15.

[6] Zhou ZY, Kizil M, Chen ZW.A new approach for selecting best development face ventilation mode based on G1-coefficient of variation method. Journal of Central South University,2018,25(10):24622471.

[7] Bao XY, Chai NJ, Wang QC. Comprehensive Effect of energy-saving measures on railway green construction based on G1 method and improved DEA models. Journal of the China Railway Society, 2018,40(10):15-22.

[8] Saaty TL. Multicriteria decision making. RWS Publications, Pittsburgh,PA,1990.

[9] Saaty TL. Decision making with dependence and feedback. RWS Publication,Pittsburgh,PA,1996.

[10] Farias, Souza LM, Santos, et al. An ANP-based approach for lean and green performance assessment. Resources Conservation and Recycling, 2019, 143:77-89.

[11] Guo RC, Zhao XJ, Zhang ZH. Three-dimensional matrix model for risk assessment on operation of Chinese train control system. Journal of the China Railway Society,2017,39(05):78-83.

[12] Wu X, He YG, Zhang DB,et al. Transformer condition assessment based on optimal weight and radar map. Power System Protection and Control,2017,45(02):55-60. 